\title{
Intense photoluminescence from erbium-doped tantalum oxide thin films deposited by sputtering
}

\author{
Mayank Kumar Singh ${ }^{1 \mathrm{a})}$, Genjoh Fusegi ${ }^{1}$, Kazusa Kano ${ }^{1}$, \\ Jaspal Parganram Bange ${ }^{2}$, Kenta Miura ${ }^{1}$, and Osamu Hanaizumi ${ }^{1}$ \\ ${ }^{1}$ Graduate School of Engineering, Gunma University, Kiryu-shi 376-8515, Japan \\ 2 Advance Technology Research Center, Gunma University, Kiryu-shi 376-8515, \\ Japan \\ a)mayank@el.gunma-u.ac.jp
}

Abstract: Erbium-doped tantalum oxide films were prepared by radio-frequency magnetron sputtering. Visible light emission was observed from the films after annealing. We obtained PL peaks at 550 and $670 \mathrm{~nm}$. The effects of erbium concentration, annealing temperature, and annealing time on the light-emitting properties of the films are discussed. The strongest intensities of the 550 and $670 \mathrm{~nm}$ peaks were observed from the samples with 0.96 and $0.63 \mathrm{~mol} \%$ erbium concentrations after annealing at $900^{\circ} \mathrm{C}$ for $20 \mathrm{~min}$, respectively.

Keywords: erbium, tantalum oxide, photoluminescence, annealing, sputtering

Classification: Optoelectronics, Lasers and quantum electronics, Ultrafast optics, Silicon photonics, Planar lightwave circuits

\section{References}

[1] L. Pavesi and D. J. Lockwood, Silicon Photonics, Springer, vol. 94, 2004.

[2] O. Hanaizumi, K. Miura, M. Saito, T. Sato, S. Kawakami, E. Kuramochi, and S. Oku, "Frontiers related with automatic shaping of photonic crystals," IEICE Trans. Electron., vol. E83-C, no. 6, pp. 912-919, June 2000.

[3] T. Sato, K. Miura, N. Ishino, Y. Ohtera, T. Tamamura, and S. Kawakami, "Photonic crystals for the visible range fabricated by autocloning technique and their application," Opt. Quantum Electron., vol. 34, no. 1, pp. 63-70, Jan. 2002.

[4] K. Miura, H. Miyazaki, and O. Hanaizumi, "Observation of blue-light emission from tantalum oxide films deposited by using radio-frequency magnetron sputtering," IEICE Trans. Electron., vol. E91-C, no. 10, pp. 1669-1672, Oct. 2008.

[5] M. Zhu, Z. Zhang, and W. Miao, "Intense photoluminescence from amorphous tantalum oxide films," Appl. Phys. Lett., vol. 89, no.2, 021915 July 2006.

[6] K. Kojima, S. Yoshida, and H. Shiraishi, "Green upconversion fluorescence in $\mathrm{Er}^{3+}$-doped $\mathrm{Ta}_{2} \mathrm{O}_{5}$ heated gel," Appl. Phys. Lett., vol. 67, no. 23, pp. 3423-3425, Dec. 1995. 
[7] H. Rigneault, F. Flory, S. Monneret, S. Robert, and L. Roux, "Fluorescence of thin films doped by kilo-electron-volt Er implantation: application to microcavities," Appl. Opt., vol. 35, no. 25, pp. 5005-5012, Sept. 1995.

[8] N. Maeda, N. Wada, H. Onoda, A. Maegawa, and K. Kojima, "Preparation and optical properties of sol-gel derived $\mathrm{Er}^{3+}$ doped $\mathrm{Al}_{2} \mathrm{O}_{3}-\mathrm{Ta}_{2} \mathrm{O}_{5}$ films," Opt. Mater., vol. 27, no. 12, pp. 1851-1858, Feb. 2005.

[9] E. Desurvire (ed.), Erbium doped fiber amplifiers, Wiley, New York, 1994.

[10] W. Xu, S. Dai, L. M. Toth, G. D. D. Cul, and J. R. Peterson, "Green upconversion emission from $\mathrm{Er}^{3+}$ ion doped into sol-gel silica glasses under red light $(647.1 \mathrm{~nm})$ excitation," J. Phys. Chem., vol. 99, no. 13, pp. 4447-4450, March 1995.

[11] Y.-L. Lu, Y.-Q. Lu, and N.-B. Ming, "Fluorescence and attenuation properties of $\mathrm{Er}^{3+}$-doped phosphate-glass fibers and efficient infraredto-visible up-conversion," Appl. Phys. B, vol. 62, no. 3, pp. 287-291, March 1996.

[12] A. Kishimoto, H. Sugimoto, T. Namba, and T. Kudo, "The influence of internal stress on the amorphous structure of wet-coated films derived from peroxopolytantalate solution," Thin Solid Films, vol. 204, no. 1, pp. L5-L8, Sept. 1991.

[13] JCPDS No.00-025-0922, PDF2, International center for diffraction data: Newton square, PA.

[14] S. J. Wu, B. Houng, and B. Huang, "Effect of growth and annealing temperatures on crystallization of tantalum pentaoxide film prepared by RF magnetron sputtering method," J. Alloy. Compd., vol. 475, no. 1-2, pp. 488-493, May 2009.

[15] N. Inoue, T. Ninomiya, S. Kashiwabara, and R. Fujimoto, " $\mathrm{Ta}_{2} \mathrm{O}_{5}$ thinfilms deposited by off-axis and on-axis pulsed laser deposition techniques," Appl. Phys. A, vol. 69, Supplement 1, pp. S609-S612, Dec. 1999.

[16] N. C. Stephenson and R. S. Roth, "Structural systematics in the binary system $\mathrm{Ta}_{2} \mathrm{O}_{5}-\mathrm{WO}_{3}$. V. The structure of the low-temperature form of tantalum oxide $\mathrm{L}-\mathrm{Ta}_{2} \mathrm{O}_{5}, "$ Acta Crystallog. Sect. B, vol. 27, no. 5, pp. 1037-1044, May 1971.

\section{Introduction}

Rare-earth doped thin films are drawing increasing attention for their use in amplifiers and lasers and their suitability for integrated optics. The optical properties of rare-earth ions in solids have been investigated widely and are well understood [1]. $\mathrm{Er}^{3+}$-doped materials are attracting much attention because of the search for solid-state-laser devices operating in the green region, optical devices for $3 \mathrm{D}$ displays and for waveguides which can work in telecommunication window. Recently green light emitting materials are in demand because they are useful in many applications (e.g., skypointer, unmanned aerial system, and mini projection system).

Tantalum pentaoxide $\left(\mathrm{Ta}_{2} \mathrm{O}_{5}\right)$ is well known because of its interesting optical and electrical properties. It's a promising material for visible-wavelength optoelectronic devices. $\mathrm{Ta}_{2} \mathrm{O}_{5}$ can also be used as a composition material for the $\mathrm{Ta}_{2} \mathrm{O}_{5} / \mathrm{SiO}_{2}$ photonic crystal elements, made by the autocloning 
method [2, 3]. Moreover, $\mathrm{Er}^{3+}$ is more soluble in $\mathrm{Ta}_{2} \mathrm{O}_{5}$ than silica. Recently, blue and red $[4,5]$ light emissions have been reported from $\mathrm{Ta}_{2} \mathrm{O}_{5}$ films. Some previous works reported photoluminescence around 550 and $670 \mathrm{~nm}$ from Er-doped $\mathrm{TaO}_{\mathrm{x}}\left(\mathrm{Er}-\mathrm{TaO}_{\mathrm{x}}\right)[6,7,8]$ using various fabrication techniques, such as sol-gel method and ion implantation.

In this paper, we report on the fabrication of $\mathrm{Er}-\mathrm{TaO}_{\mathrm{x}}$ films by radiofrequency $(\mathrm{RF})$ magnetron sputtering for the first time and visible light emission at 550 and $670 \mathrm{~nm}$. We optimized the fabrication and annealing conditions to obtain strong light intensity from the sputtered films. Such Er$\mathrm{TaO}_{\mathrm{x}}$ films can be used as a high-refractive-index material for autocloning type photonic crystals to realize novel light-emitting devices.

\section{Experiments}

Er- $\mathrm{TaO}_{\mathrm{x}}$ films were fabricated using an RF magnetron sputtering system, (ULVAC, SH-350-SE). A $\mathrm{Ta}_{2} \mathrm{O}_{5}$ disc (99.99\% purity, diameter $100 \mathrm{~mm}$ ) was used as a sputtering target. We placed $\mathrm{Er}_{2} \mathrm{O}_{3}$ tablets (99.9\% purity, diameter $21 \mathrm{~mm}$ ) on the $\mathrm{Ta}_{2} \mathrm{O}_{5}$ disc. $\mathrm{Ta}_{2} \mathrm{O}_{5}$ and $\mathrm{Er}_{2} \mathrm{O}_{3}$ co-sputtered films were deposited by supplying RF power to the target. The pressure in the vacuum chamber of the sputtering system was $0.54 \times 10^{-4}$ to $1.06 \times 10^{-4} \mathrm{~Pa}$, the $\mathrm{Ar}$ flow rate in the chamber was $10 \mathrm{sccm}$, and the pressure during deposition was approximately 1.1 $\mathrm{Pa}$. The RF power supplied to the target was $300 \mathrm{~W}$. Fused silica substrates (ATOCK Inc., thickness $1 \mathrm{~mm}$ ) were used. The substrates were not heated during sputtering.

The samples were annealed in ambient air from 600 to $1100^{\circ} \mathrm{C}$ for 10 to $40 \mathrm{~min}$ using an electric furnace (Denken, KDF S-70). In order to vary the Er concentration, we placed 1 to 5 tablets of $\mathrm{Er}_{2} \mathrm{O}_{3}$ on the $\mathrm{Ta}_{2} \mathrm{O}_{5}$ disc during the sputtering process. The photoluminescence (PL) of the samples was measured with a dual-grating monochromator (Roper Scientific, Spectra Pro 2150i) and a CCD detector (Roper Scientific, Pixis-100). An He-Cd laser (Kimmon, $325 \mathrm{~nm}$, max power $200 \mathrm{~mW}$ ) was used for excitation of the samples. The Er concentration in the films after annealing was measured by an electron-probe micro-analyzer (EPMA, Shimadzu EPMA-1610). The Xray diffraction (XRD) patterns of the films annealed at various temperatures were recorded by a Rigaku diffractometer using the $\mathrm{Cu} \mathrm{K} \alpha$ radiation at a scanning step of $0.02^{\circ}$.

\section{Results and discussion}

Fig. 1 (a) plots the PL spectra of Er-TaO films fabricated using two $\mathrm{Er}_{2} \mathrm{O}_{3}$ tablets and annealed from 600 to $1100^{\circ} \mathrm{C}$ for $20 \mathrm{~min}$. The as-deposited samples did not exhibit PL. We observed two PL peaks from post annealed samples at 550 and $670 \mathrm{~nm}$. The sample annealed at $900^{\circ} \mathrm{C}$ exhibits the strongest PL intensity. The PL peaks observed at 550 and $670 \mathrm{~nm}$ are due to the transitions of $\mathrm{Er}^{3+}$ from the ${ }^{4} \mathrm{~S}_{3 / 2}$ to the ${ }^{4} \mathrm{I}_{15 / 2}$ state and from the ${ }^{4} \mathrm{~F}_{9 / 2}$ to the ${ }^{4} \mathrm{I}_{15 / 2}$ state, respectively [9]. Light emission at $670 \mathrm{~nm}$ could not be observed in the samples annealed at 600 and $700^{\circ} \mathrm{C}$. 


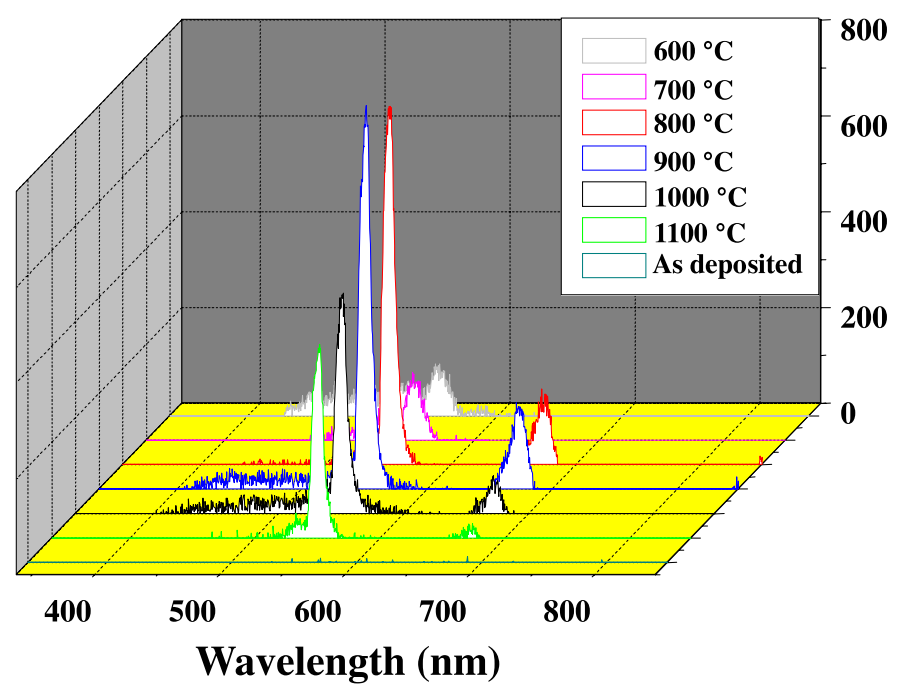

(a)

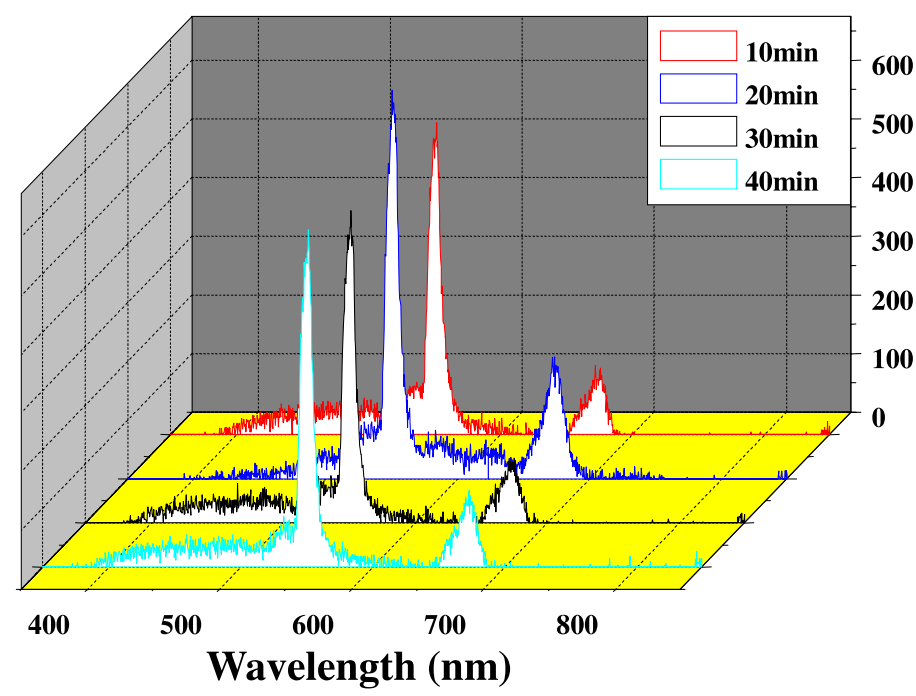

(b)

Fig. 1. PL spectra of Er- $\mathrm{TaO}_{x}$ films annealed at (a) 600 to $1100^{\circ} \mathrm{C}$ for $20 \mathrm{~min}$, and (b) $900^{\circ} \mathrm{C}$ for 10 to $40 \mathrm{~min}$.

To observe the effect of annealing time on PL intensity and to optimize the annealing time, we annealed samples (fabricated with two $\mathrm{Er}_{2} \mathrm{O}_{3}$ tablets) at $900^{\circ} \mathrm{C}$ for 10 to $40 \mathrm{~min}$ in ambient air. Fig. 1 (b) plots the PL spectra for different annealing times. The sample annealed for $20 \mathrm{~min}$ had the strongest PL intensities at both wavelengths of 550 and $670 \mathrm{~nm}$.

Fig. 2 plots the PL spectra with different Er concentrations annealed at $900^{\circ} \mathrm{C}$ for $20 \mathrm{~min}$. It has been reported that fluorescence due to $\mathrm{Er}^{3+}$ exhibits the strongest intensity at 1.2, 0.75, and $2 \mathrm{~mol} \%$ Er concentration [10, 11, 12]. In our work, we observed the strongest PL intensity with 0.96 and $0.63 \mathrm{~mol} \%$ Er concentrations at 550 and $670 \mathrm{~nm}$, respectively. Table I shows the detailed results of Er concentrations in different samples measured with EPMA.

We observed an increase in Er concentration with the increasing number 
Table I. Concentration of Er in different samples measured with EPMA.

\begin{tabular}{|l|c|c|c|c|c|}
\hline $\begin{array}{l}\text { Number of } \mathrm{Er}_{2} \mathrm{O}_{3} \text { tablet } \\
\text { on } \mathrm{Ta}_{2} \mathrm{O}_{5} \text { disc }\end{array}$ & 1 & 2 & 3 & 4 & 5 \\
\hline Er concentration (mol \%) & $\mathbf{0 . 4 6}$ & $\mathbf{0 . 6 3}$ & $\mathbf{0 . 9 6}$ & 1.32 & 2.08 \\
\hline
\end{tabular}

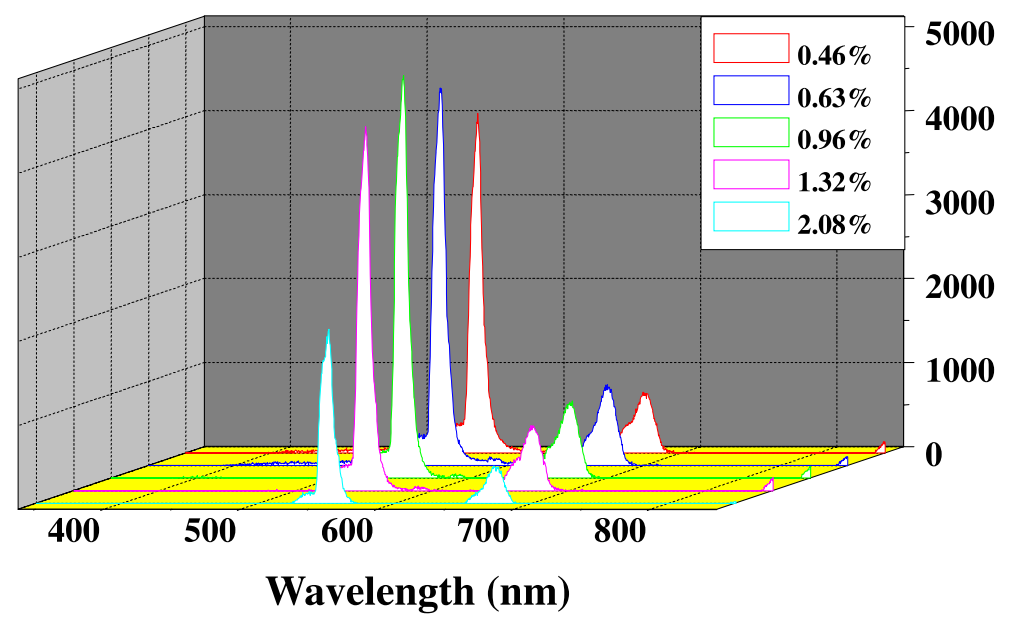

Fig. 2. PL spectra of samples with different Er concentrations $(\mathrm{mol} \%)$ annealed at $900^{\circ} \mathrm{C}$ for $20 \mathrm{~min}$.

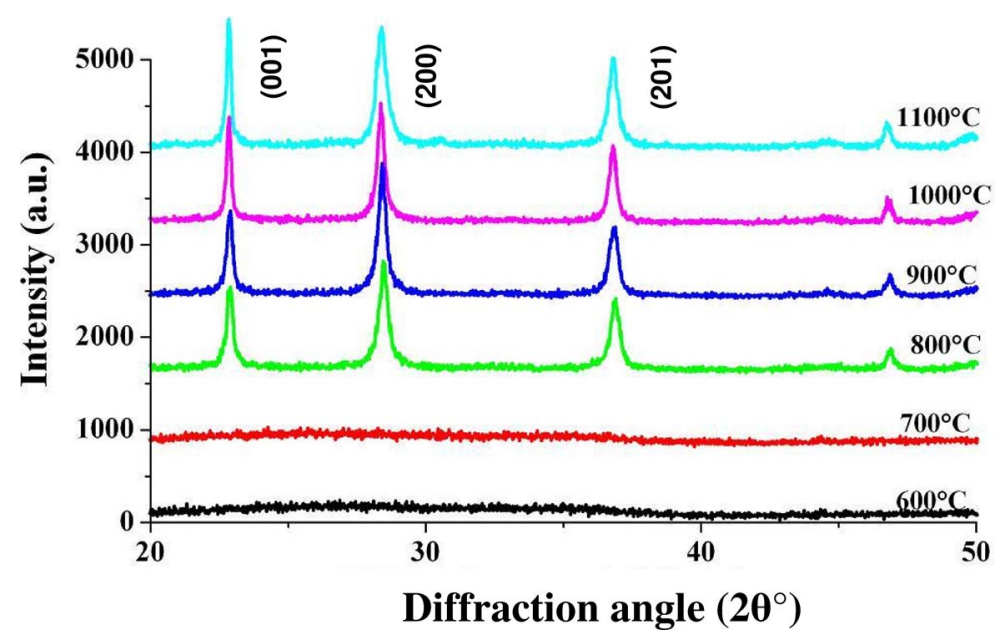

Fig. 3. XRD patterns of the films annealed at various temperatures.

of $\mathrm{Er}_{2} \mathrm{O}_{3}$ tablets on the $\mathrm{Ta}_{2} \mathrm{O}_{5}$ disc. It appears that different fabrication methods and dissolution sites of Er in the host material affect the Er concentration required to optimally enhance the PL intensity.

Fig. 3 shows the XRD patterns of the films annealed at various temperatures. The diffraction pattern fits well with references 13 and 14 . The absence of $2 \boldsymbol{\theta}$ peaks in samples annealed below $800^{\circ} \mathrm{C}$ indicates amorphous $\mathrm{Ta}_{2} \mathrm{O}_{5}$ film formation. XRD patterns of the samples annealed at 800 and $900^{\circ} \mathrm{C}$ probably show a mixed phase of $\delta$ - $\mathrm{Ta}_{2} \mathrm{O}_{5}$ (hexagonal, low-temperature phase) and $\beta-\mathrm{Ta}_{2} \mathrm{O}_{5}$ (orthorhombic, high-temperature phase) [15]. High PL intensities 
in the samples annealed at 800 and $900^{\circ} \mathrm{C}$ could be a result of crystallization of the films. We can observe a change in intensity of the first peak $\left(2 \boldsymbol{\theta}=23^{\circ}\right)$ in the samples annealed at 1000 and $1100^{\circ} \mathrm{C}$. In the samples annealed at 1000 and $1100^{\circ} \mathrm{C}, \beta-\mathrm{Ta}_{2} \mathrm{O}_{5}$ (orthorhombic) grew more than $\delta-\mathrm{Ta}_{2} \mathrm{O}_{5}$ (hexagonal), therefore a change in intensity was observed.

As discussed earlier, about some previous works reported PL from Er$\mathrm{TaO}_{\mathrm{x}}$ films. Rigneault et al [7] reported fluorescence spectra centered at 532 and $1530 \mathrm{~nm}$ from Er- $\mathrm{TaO}_{\mathrm{x}}$ samples fabricated with ion implantation. Kojima et al [6] also observed a green fluorescence peak around $550 \mathrm{~nm}$ from samples fabricated with sol-gel process. Maeda et al [8] also reported fluorescence spectra around $550 \mathrm{~nm}$ and a weak peak around $660 \mathrm{~nm}$ with sol-gel process. In comparison to these previous works, we observed two very sharp PL peaks at 550 and $670 \mathrm{~nm}$. Moreover, we observed visible green light emission by the naked eye which was not reported previously. This concludes that PL intensity at $550 \mathrm{~nm}$ is stronger in our results than previously reported works. Sputtering method has some advantages over the other deposition methods as the films deposited by sputtering have a composition close to that of the source material. Sputtered films have a better adhesion on the substrate than the evaporated films. In addition, the sputtering method is more suitable for mass production as it requires a single target and the films are relatively less contaminated.

$\mathrm{TaO}_{\mathrm{x}}$ is superior to $\mathrm{SiO}_{2}$ and $\mathrm{GeO}_{2}$ in terms of both the phonon energy and $\mathrm{Er}^{3+}$ solubility. Amorphous $\mathrm{Ta}_{2} \mathrm{O}_{5}$ has better $\mathrm{Er}^{3+}$ solubility than $\mathrm{SiO}_{2}$ because of the relatively large amount of edge oxygen having a negative charge [12]. The crystalline bulk phase of $\mathrm{Ta}_{2} \mathrm{O}_{5}$ is known to exist below $1630 \mathrm{~K}$ [16], but its crystal structure is not uniquely determined. Processing conditions and impurities have subtle effects on the crystal structure and light emission. It is surmised that the change in light intensity of films after annealing is the result of changes in the phase, the crystal structure, and the dissolution site of $\mathrm{Er}^{3+}$ in the $\mathrm{Ta}_{2} \mathrm{O}_{5}$.

\section{Conclusion}

We fabricated Er- $\mathrm{TaO}_{\mathrm{x}}$ films using the RF-sputtering method and then annealed them at various temperatures and time durations. PL peaks were observed at wavelengths of 550 and $670 \mathrm{~nm}$. We observed the strongest intensities of the 550 and $670 \mathrm{~nm}$ peaks from the samples with 0.96 and $0.63 \mathrm{~mol} \%$ Er concentrations after annealing at $900^{\circ} \mathrm{C}$ for $20 \mathrm{~min}$, respectively. To the best of our knowledge, this is the first report of light emission from $\mathrm{Er}-\mathrm{TaO}_{\mathrm{x}}$ films fabricated by the RF-sputtering method.

These results demonstrate that $\mathrm{Er}-\mathrm{TaO}_{\mathrm{x}}$ films fabricated by $\mathrm{RF}$ sputtering can serve as high-quality luminescent layers. These can easily be combined with other passive devices to realize novel active devices (e.g., a greenlight-emitting photonic crystals), as only sputtering and annealing processes are needed for fabrication. 


\section{Acknowledgments}

This work was supported by a Grant-in-Aid for Scientific Research (C) from the Japan Society for the Promotion of Science; a Grant-in-Aid for Young Scientists (B) from the Ministry of Education, Culture, Sports, Science and Technology; and the MIKIYA Science and Technology Foundation. Part of this work was conducted in the Advanced Technology and Education Center (ATEC) and the Center for Material Research by Instrumental Analysis (CIA) at Gunma University.

The authors would like to thank Prof. Manabu Takahashi, Graduate School of Engineering, Gunma University, for stimulating discussions. 